\title{
Comparative Study between Multidetector Computed Tomography (MDCT) Angiography and Echocardiography in Assessment of Cardiac Anomalies Associated with Aortic Coarctation
}

\author{
ABRAR EL-SALLAKH, MSc.*; ELATAFY E. ELATAFY, M.D.**; HOSSAM ZAYTOUN, M.D.* and \\ MOHAMMED DAWOUD, M.D.* \\ The Departments of Radiodiagnosis \& Medical Imaging* and Cardiothoracic Surgery**, Faculty of Medicine, Tanta University
}

\begin{abstract}
Background: In patients with aortic coarctation, it is important for preoperative detection of associated cardiac anomalies. MDCT and echocardiography are currently the most reliable methods of diagnosis.

Aim of Study: To evaluate the role of multidetector computed tomography (MDCT) angiography in assessment of associated cardiac anomalies in cases of aortic coarctation as compared to echocardiography.

Patients and Methods: Sixty patients that were known to have aortic coarctation underwent MDCT for assessment of associated cardiac anomalies. MDCT angiography findings were compared with both Doppler echocardiography and surgical results.

Results: There was a $30 \%$ agreement between the findings of MDCT angiography and echocardiography in detection of extracardiac vascular anomalies and a $68 \%$ agreement in detection of intracardiac anomalies.

Conclusion: Considering MDCT angiography the modality of choice in detection of extracardiac vascular anomalies showing higher sensitivity $(100 \%)$ while the echocardiography is of choice in detection of intracardiac anomalies with $100 \%$ sensitivity.
\end{abstract}

Key Words: Aortic coarctation (CoA) - Congenital heart diseases (CHD) - Patent ductus arteriosus (PDA) - Left superior vena cava (LSVC).

\section{Introduction}

COARCTATION of the aorta is a congenital malformation and typically a disease of childhood and early adulthood [1]

Correspondence to: Dr. Abrar El-Sallakh, The Department of Radiodiagnosis \& Medical Imaging, Faculty of Medicine, Tanta University
CoA is classified as "simple" when isolated and "complex" when associated with additional cardiac anomalies, typically involving the left side of the heart. The defects most commonly seen with coarctation are bicuspid aortic valve and ventricular septal defect. Coarctation may also be seen as a part of more complex single ventricle heart defects $[2,3]$.

MDCT with multiplanar and three dimensional techniques is the non-invasive method of choice for assessing the associated cardiovascular abnormalities. It is important to have accurate information to decide surgical or interventional repair $[\mathbf{5 , 6 ]}$.

\section{Patients and Methods}

A prospective study was performed 60 patients (36 males and 24 females) with male to female ratio: $60 \%$ to $40 \%$. The age of the patients ranged from 0.3 to 204 months with mean age $13.9 \pm 45.9$. They were diagnosed to have aortic coarctation. Patients were referred to Tanta University Hospital from pediatric cardiology and cardio-thoracic departments during the period from March 2017 to March 2018 in order to undergo cardiac MDCT. They all underwent Doppler echocardiography. Ethics committee approval and informed consent were obtained.

\section{Inclusion criteria:}

Patients clinically suspected or echocardiography diagnosed to have aortic coarctation.

\section{Exclusion criteria:}

- Patient who is clinically unstable to withstand the duration of CT examination. 
- Patient with history of allergy to intravenous contrast media that will be used.

- Patient who has impaired renal function (Creatinine level $\geq 1.5 \mathrm{mg} / \mathrm{dl}$ ).

- Patients with bad general condition needing life support.

MSCT were performed using (Aquilion One, Toshiba Medical Systems, Otawara, Japan) 320slices spiral CT scanner.

Patients below 4 years or who are uncooperative were orally sedated by administration of chloral hydrate $(50-100 \mathrm{mg} / \mathrm{kg}$; maximum dose, $2000 \mathrm{mg}$ ) or I.V. administrated phenobarbital sodium $(6 \mathrm{mg} /$ $\mathrm{kg}$; maximum dose 200mg). Older children were responding satisfactorily to verbal reassurance and be able to completely suspend respiration.

All patients underwent cardiac CT angiography (CCTA) with the patient in supine position. Data acquisition was retrospectively ECG triggered. A scanogram was obtained and scan range from the root of the neck including the proximal aspect of common carotid and subclavian arteries down to the level of portal vein inferiorly.

\section{Contrast medium administration:}

Suitable size IV line cannula was inserted in right antecubital fossa then intravenous injection of omnipaque 350mg Iodine/ml (Iohexol, GE health care Ireland, Cork, Ireland) was used. The volume of contrast injected is weight based $2 \mathrm{~mL} / \mathrm{kg}$ with dilution of contrast material by normal saline $1 \mathrm{ml} / \mathrm{kg}$ (2:1 ratio of contrast material and normal saline solution) using automatic injector (Stellant $\mathrm{D}$, Medrad, Indianola, PA, USA) at rate of $1.0 \mathrm{ml} / \mathrm{s}$ for younger children to $3.0 \mathrm{ml} / \mathrm{s}$ for older children.

Manual Bolus tracking was applied 10 to 15 seconds after contrast injection (for upper limb venous line) and after 20 seconds (for lower limb venous line), the scan is initiated after opacification of both ventricles.

CT angiography was interpreted on dedicated workstations. Maximum intensity projections (MIP), three dimensional volume rendering (VR), multiplanar (MPR) and curved planer reformations (CPR) were used to display heart malformations.

Surgery was performed in all 60 patients. MSCT results were compared with both Doppler echocardiography and surgical results.
Statistical analysis:

Statistical analysis of the present study was conducted by SPSS V.20. Qualitative data was presented using number and percentage. Quantative data presented as mean and standard deviation (SD).

For categorical variables, Chi-square test was used for analysis The level of significance was adopted at $p<0.05$.

Pearson statistical correlation between CoA diameter/AAD (Aorta at diaphragm diameter) and various patient's parameters was also done.

1-Mean value: The sum of all observations divided by the number of observations.

$$
\mathrm{X}=\frac{\sum \mathrm{X}}{\mathrm{N}}
$$

Where $\sum=$ Sum $\& \mathrm{n}=$ Number of observations.

2- Standard Deviation (SD): It measures the degree of scatter individual varieties around their mean.

$$
\mathrm{SD}=\sqrt{\sum_{\mathrm{N}-1}^{(\mathrm{x}-\mathrm{x})^{2}}}
$$

\section{Results}

In our study we enrolled 60 patients (36 males and 24 females) with male to female ratio: $60 \%$ to $40 \%$. The age of the patients ranged from 0.3 to 204 months with mean age $13.9 \pm 45$.9. The weight of the patients ranges from 3 to $65 \mathrm{Kg}$ with mean weight $7.6 \pm 13.8$.

In our results, the most common congenital intra cardiac anomalies detected in patients with aortic coarctation was atrial and ventricular septal defects (39 cases). 12 cases (20\%) had atrial septal defect, 6 cases $(10 \%)$ had ventricular septal defect and 21 cases $(35 \%)$ had both atrial and ventricular septal defects. 6 out of 33 cases with ASD were missed by MDCT but diagnosed by Doppler echocardiography. All cases of VSD were correctly diagnosed by both MSCT angiography and Doppler echocardiography with $100 \%$ sensitivity. Two case with subvalvular aortic membrane were also correctly diagnosed by both MDCT and echocardiography. The overall sensitivity of MDCT for the assessment of intra cardiac anomalies was (68\%) which was lower than that of Doppler echocardiography (100\%) (Table 1). Chi square test revealed non-statistically significant difference between Echo and CT in detection of intra-cardiac defects $(p=0.6)$. 
Table (1): Comparison between detection of associated intracardiac anomalies by MSCT and Echo.

\begin{tabular}{|c|c|c|c|c|c|c|}
\hline \multirow{2}{*}{$\begin{array}{l}\text { Associated intra- } \\
\text { cardiac anomalies }\end{array}$} & \multicolumn{2}{|c|}{ MSCT } & \multicolumn{2}{|c|}{ Echo } & \multirow{2}{*}{$x^{2}$} & \multirow{2}{*}{$p$} \\
\hline & No. & $\%$ & No. & $\%$ & & \\
\hline None & 19 & 31.7 & 13 & 21.7 & 2.325 & 0.676 \\
\hline ASD & 12 & 20.0 & 18 & 30.0 & & \\
\hline VSD & 6 & 10.0 & 6 & 10.0 & & \\
\hline $\mathrm{ASD}, \mathrm{VSD}$ & 21 & 35.0 & 21 & 35.0 & & \\
\hline $\begin{array}{l}\text { Subvalvular aortic } \\
\text { membrane }\end{array}$ & 2 & 3.3 & 2 & 3.3 & & \\
\hline
\end{tabular}

The most common congenital extra cardiac vascular anomalies detected in patients with aortic coarctation was PDA (17 cases) (28\%) followed by persistent left superior vena cava ( 7 cases) $(11.7 \%)$, vertebral artery arising directly from the aortic arch (4 cases) $(6.7 \%)$, persistent left superior vena cava together with aberrant right subclavian artery (3 cases) (5\%), anomalous origin of the left coronary artery (2case) $(3.3 \%)$. All cases of patent ductus arteriosus were correctly diagnosed by both MSCT angiography and Doppler echocardiography with $100 \%$ sensitivity. Echocardiography missed the diagnosis of all other extracardiac vascular anomalies that were correctly diagnosed by MSCT. The overall sensitivity of MSCT for the assessment of extracardiac vascular anomalies was $(100 \%)$ which was higher than that of Doppler echocardiography (30\%) (Table 2). Chi square test revealed statistically significant difference between Echo and $\mathrm{CT}$ in detection of extra-cardiac anomalies $(p=0.018)$.

Table (2): Comparison between detection of associated extracardiac anomalies by MSCT and Echo.

\begin{tabular}{|c|c|c|c|c|c|c|}
\hline \multirow{2}{*}{$\begin{array}{l}\text { Associated extra- } \\
\text { cardiac anomalies }\end{array}$} & \multicolumn{2}{|c|}{ MSCT } & \multicolumn{2}{|c|}{ Echo } & \multirow{2}{*}{$x^{2}$} & \multirow{2}{*}{$\mathrm{MC}_{p}$} \\
\hline & No. & $\%$ & No. & $\%$ & & \\
\hline None & 27 & 45.0 & 42 & 70.0 & $18.535^{*}$ & $<0.001 *$ \\
\hline PDA & 17 & 28.3 & 18 & 30.0 & & \\
\hline Persistent LSVC & 7 & 11.7 & 0 & 0.0 & & \\
\hline $\begin{array}{l}\text { Vertebral artery } \\
\text { from arch }\end{array}$ & 4 & 6.7 & 0 & 0.0 & & \\
\hline $\begin{array}{l}\text { Aberrant RT SCA } \\
\text { and persistent LT } \\
\text { SVC }\end{array}$ & 3 & 5.0 & 0 & 0.0 & & \\
\hline $\begin{array}{l}\text { Anomalous origin } \\
\text { of the left coro- } \\
\text { nary artery }\end{array}$ & 2 & 3.3 & 0 & 0.0 & & \\
\hline
\end{tabular}

\section{Illustrated cases:}
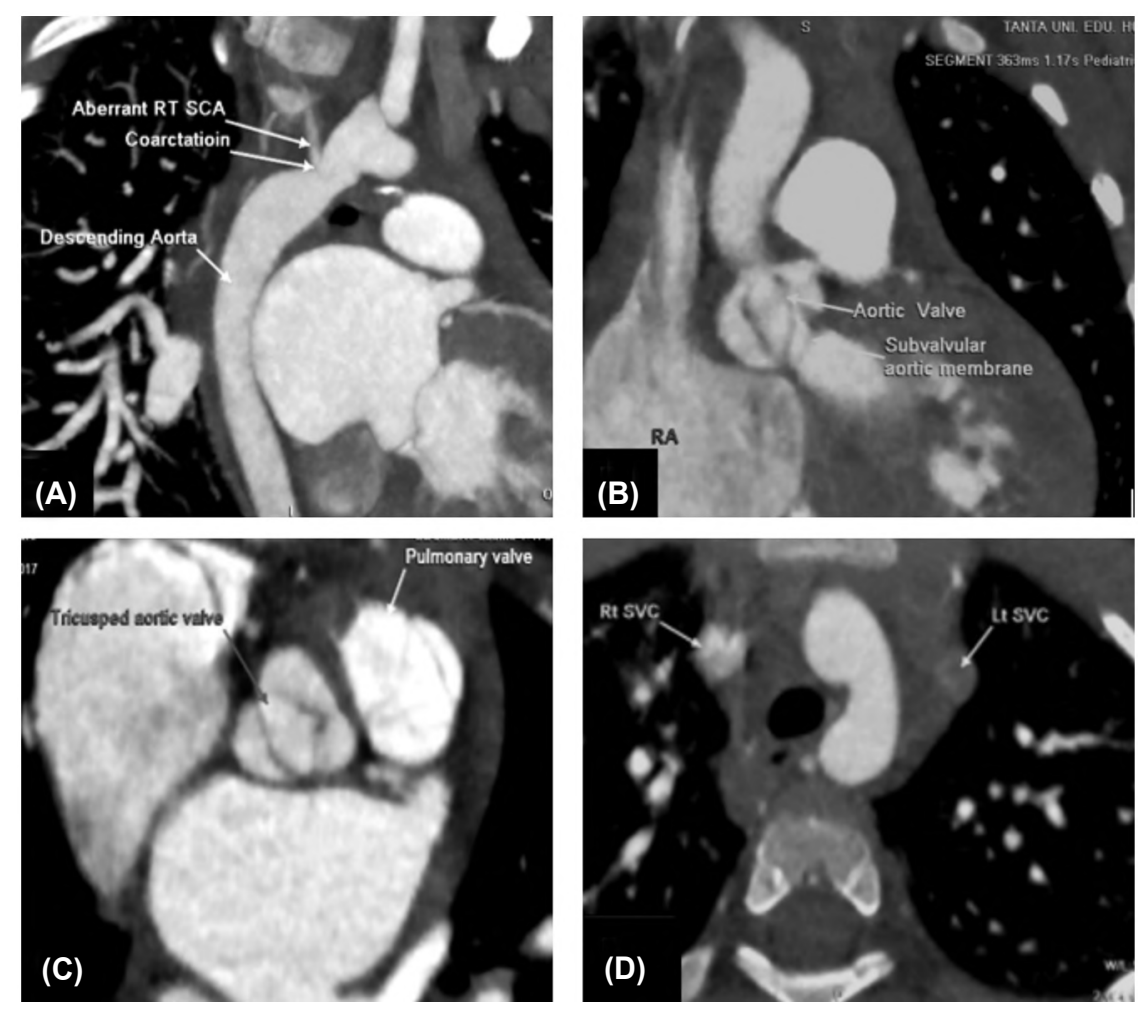

Fig. (1): Male patient aged 4 years presented with dyspnea and palpitation. (A) CPR image showing focal aortic coarctation opposite the origin of the aberrant right subclavian artery. (B) CPR image showing subvalvular aortic membrane. (C) Axil MSCT image showing trileaflet aortic valve. (D) Axil MSCT image showing persistent left superior vena cava. 


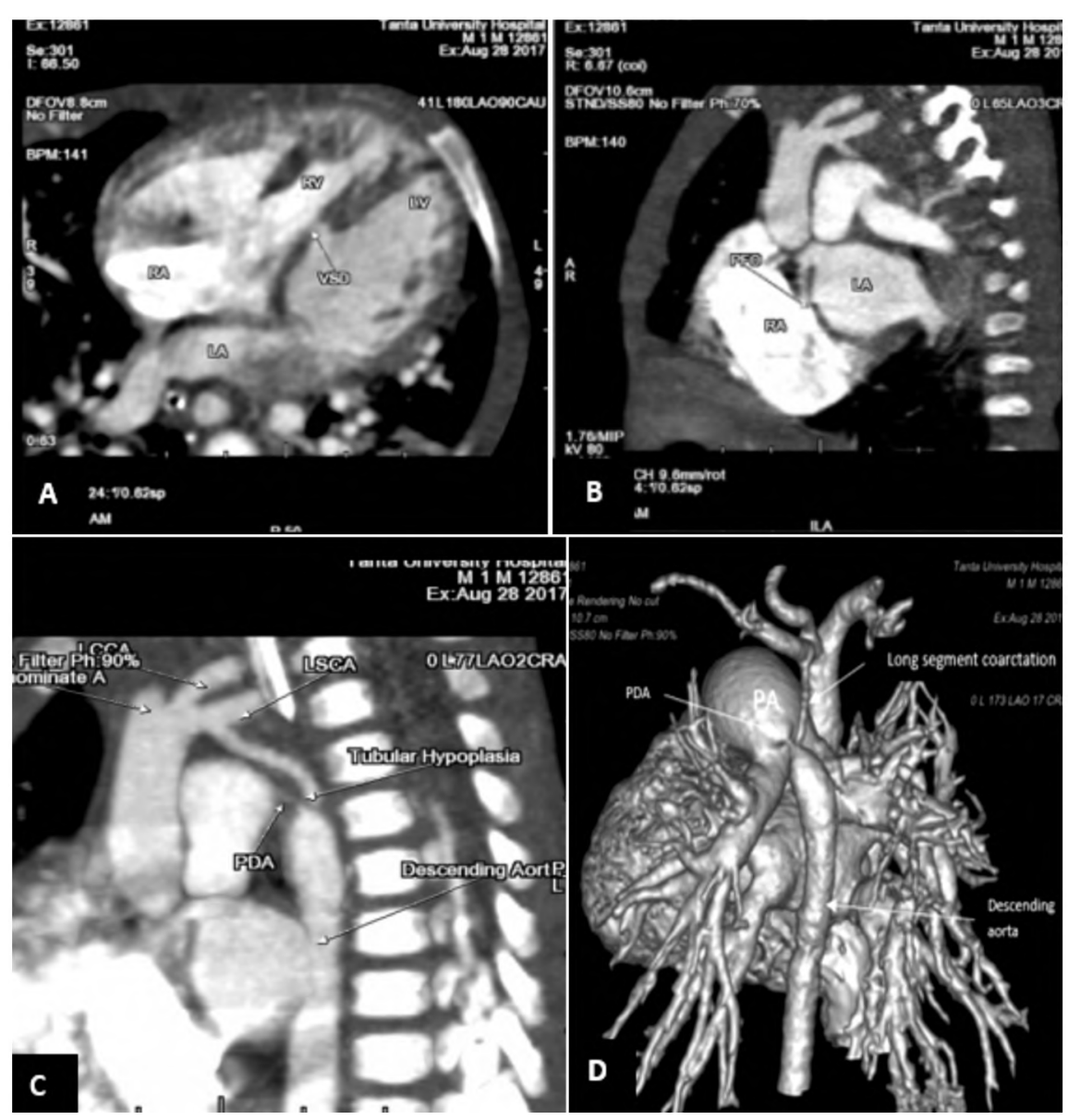

Fig. (2): Male patient aged 3 months presented with dyspnea and murmur. (A) CPR image showing VSD, (B) CPR image showing PFO, (C\&D) CPR with MIP and 3D images showing long segment aortic arch coarctation distal to the origin of the left subclavian artery with PDA.
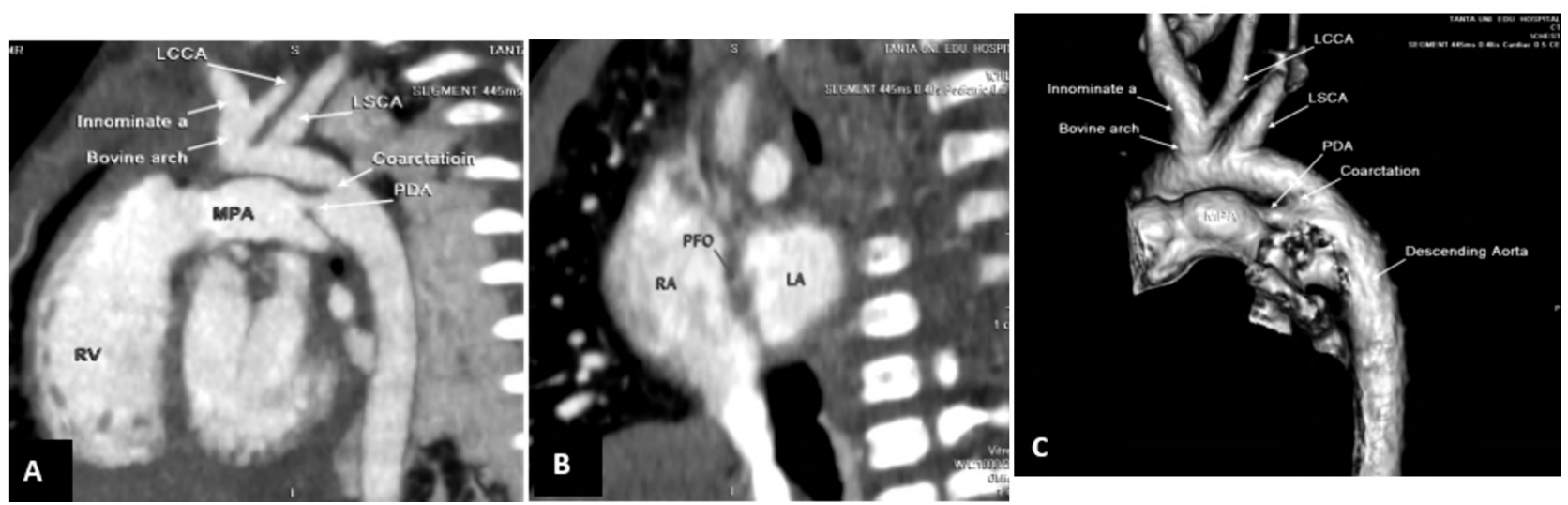

Fig. (3): Female patient aged 20 days presented with murmur. (A) CPR image with MIP showing mild focal aortic coarctation distal to the origin of the left subclavian artery with post stenotic dilation, PDA. (B) CPR image showing patent foramen ovale. (C) Volume rendering MSCT image showing mild focal aortic coarctation distal to the origin of the left subclavian artery, PDA.

\section{Discussion}

MDCT with multiplanar and three-dimensional techniques provide morphologic images of coarctation of the aorta and associated congenital cardiac anomalies [5,6].
In our study, 60 patients (36 males and 24 females) with an age range between 9 days to 17 years were included (mean age $13.9 \pm 45.9$ months). All patients included in this study were initially examined by echocardiography then by MSCT followed by surgical repair. 
In the present study, we found that the most common intra cardiac anomalies associated with aortic coarctation was septal defects $(65 \%)$, and this agreed with the study of Hu et al., [5] in which septal defects were detected in (75\%) and Türkvatan et al., [7] who reported that the highest incidence (25\%) was with septal defects.

In our work, all cases of VSD and the 2 cases of subvalvular aortic membrane were diagnosed by both MSCTA and echocardiography while 6 out of 33 cases with ASD were missed by MDCT but diagnosed by Doppler echocardiography, which are confirmed by surgery. In the current study, the sensitivity of MSCT diagnosis of intra cardiac anomalies was $68 \%$, which was lower than that of echocardiography $(100 \%)$. This was in line with Hu et al., [5] who stated that the overall sensitivity of MDCT for the assessment of intracardiac malformations $(91.7 \%)$ which was lower than that of the echocardiography (100\%) and Türkvatan et al., [7] who also reported that MDCT missed the diagnosis of one case of VSD making the overall sensitivity of MDCT in assessment of intracardiac malformations $(83.3 \%)$ which was lower than that of the echocardiography (100\%).

In the present study, we found that the most common extra cardiac vascular anomalies associated with aortic coarctation was PDA (17 cases) (28\%), and this agreed with the study of $\mathrm{Hu}$ et al., [5] in which PDA was detected in $(37 \%)$ while Türkvatan et al., [7] reported that the highest incidence $(20 \%)$ was with PDA.

All cases of PDA in our work were diagnosed by both MSCTA and echocardiography, all other extracardiac anomalies was only diagnosed by MSCT and were missed by echocardiography which are confirmed by surgery, this was in agreement with $\mathrm{Hu}$ et al., [5] who reported similar results. In the current study, the sensitivity of MSCT diagnosis of extracardiac anomalies was $100 \%$, which was higher than that of echocardiography (30\%). This was also in line with $\mathrm{Hu}$ et al., [5] and Türkvatan et al., [7].
From this study we agreed with Goo et al., [8] who concluded that although echocardiography is the method of choice for diagnosing the vast majority of congenital cardiac abnormalities, CT plays an increasing complementary role by providing objective and accurate morphologic and functional information and is useful for detecting extracardiac abnormalities thus helping in pre-operative planning and post-operative assessment of congenital heart disease patients.

\section{Conclusion:}

MDCT angiography the modality of choice in detection of extracardiac vascular anomalies while the echocardiography is of choice in detection of intracardiac anomalies.

\section{References}

1- FIXLER D.: Coarctation of the aorta. Cardiol. Clin., 6: 561-571, 1998.

2- SEBASTIA C., QUIROGA S., BOYE R., et al.: Aortic stenosis: Spectrum of diseases depicted at multisection CT. Radiographics, 23: 79-91, 2003.

3- BENYOUNES N., BLANC R., BOISSONNET H., et al.: Subarachnoid hemorrhage revealing aortic coarctation in a young man. Neuroradiology, 53: 931-93, 2011.

4- WARNES C.A., WILLIAMS R.G., BASHORE T.M., et al.: ACC/AHA 2008 guidelines for the management of adults with congenital heart disease. Journal of the American College of Cardiology, 52: 143-263, 2008.

5- HU X.H., HUANG GY., PA M., et al.: Multidetector CT angiography and $3 \mathrm{D}$ reconstruction in young children with coarctation of the aorta. Pediatr. Cardiol., 29: 726731,2008

6- UTAK O., KARACA M., BAYTURAN O., et al.: Coarctation of the aorta evaluated with 64-row multislice computed tomography. Int. J. Cardiol., 111: 169-71, 2006.

7- TÜRKVATAN A., AKDUR P., ÖLÇER T., et al.: Coarctation of the aorta in adults: preoperative evaluation with multidetector CT angiography. Diagn. Interv. Radiol., 15: 269-274, 2009.

8- GOO H.W.: State of the art CT imaging techniques for congenital heart disease. Korean. J. Radiol., 11: 4-18, 2010 . 


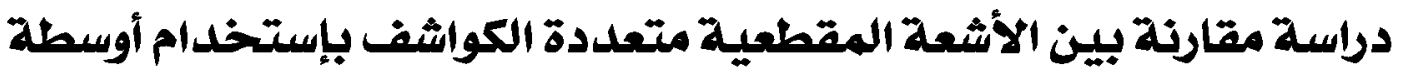

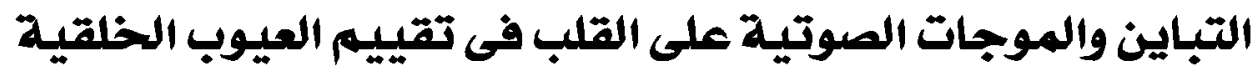

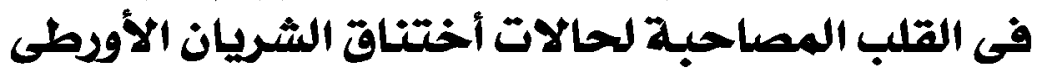

أشتملت هذه الدراسة على ستين مريضاً، ستة وثلاثين ذكراً وأربعة وعشرين أنثى بمتوسط أعمار من عشر أيام إلى سبعة عشر عاماً. خضع كل المرضى للفحص الاكلينيكى للقلب وكذلك الفحص عن طريق الموجات الصوتية للقلب ثم للفحص عن طريق الأشعة المقطعية متعدة المقاطع للقلب والشرايين.

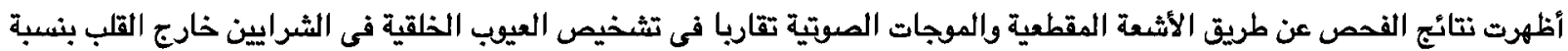
تصل إلى ثمانية وستون بالمائة، ونسبة تصل إلى ثلاثين فى المائة فى تشخيص العيد العيوب الخلقية الداخلية للقلب.

ولالك فقد أظهرت الأشعة المقطعية متعددة المقاطع تفوقها في تشخيص العيوب الخلقية فى الشرايين خارج القلب بينما أظهر الفحص

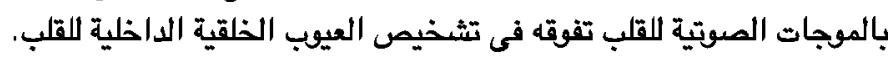

